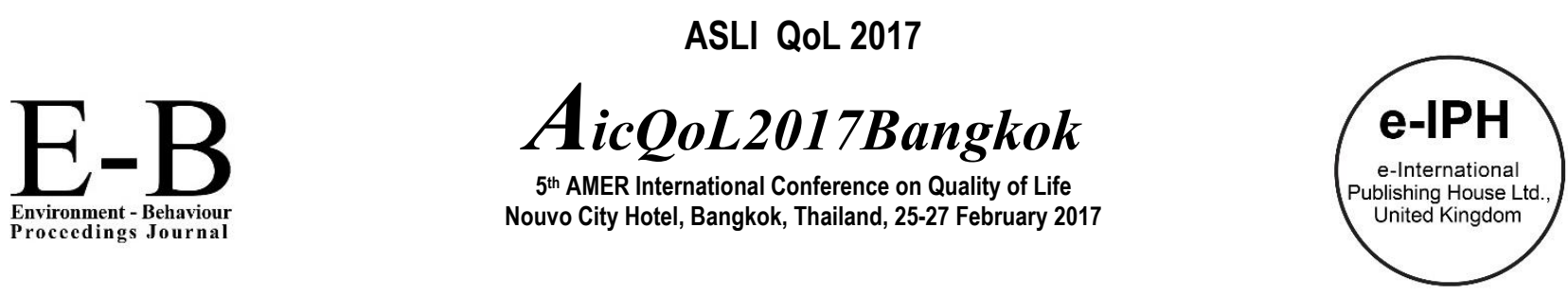

\title{
Community Participations in Amphawa Comprehensive Planning, Thailand
}

\author{
Wannasilpa Peerapun* \\ Faculty of Architecture, Chulalongkorn University, Phya Thai Road, Bangkok 10330, Thailand
}

\begin{abstract}
The aim of this article was to discuss community participations in Amphawa comprehensive planning, Thailand, which targeted for the year 2030. There were two objectives of the study-to discuss the effectiveness of community participations and to discuss the future land use plan. The planning methodology integrated several community participation activities into the traditional comprehensive planning process. The result of the study revealed that community participations helped reduce difficulties and save time. In terms of future land uses, several conservation related zones were designated to conserve local natural and cultural heritages and agricultural areas.
\end{abstract}

Keywords: Community participations; Comprehensive planning; Amphawa

ISSN: 2398-4287@ 2017. The Author. Published for AMER ABRA by e-International Publishing House, Ltd., UK. This is an open access article under the CC BYNC-ND license (http://creativecommons.org/licenses/by-nc-nd/4.0/). Peer-review under responsibility of AMER (Association of Malaysian Environment-Behaviour Researchers), ABRA (Association of Behavioural Researchers on Asians) and CE-Bs (Centre for Environment-Behaviour Studies), Faculty of Architecture, Planning \& Surveying, Universiti Teknologi MARA, Malaysia.

\subsection{Introduction}

Comprehensive planning in Thailand is a very complicate task which requires many steps mandated by law and a lengthy procedure outlined by ministerial and departmental orders. Community participations in general comprehensive planning are usually limited. Public hearings are usually held after the draft plan is completed, not during the stage of plan making. The lack of appropriate community participation procedure and tools have increased difficulties in the process of comprehensive planning in Thailand. More conflicts have arisen frequently resulting in negative attitudes of local citizens towards comprehensive planning.

Amphawa comprehensive plan for the year 2030, prepared by a planning team from the Faculty of Architecture, Chulalongkorn University during the years 2010 and 2013, was an attempt to deal with the problems of community participations and their consequences in Thailand. The plan was developed to replace the expired one which was implemented during the years 2002 and 2007. The new Amphawa Comprehensive Plan, targeting for the year 2030, covered an area of 169 square kilometers in Amphawa District, Samut Songkhram Province. The planning area comprised several small municipalities and sub-districts, orchards, fish ponds, mangroves and intensive water networks. Participatory action research approach was integrated into the comprehensive planning procedure mandated by the Office of Public Construction and Town Planning while the core planning concept inherited "Sufficiency Economy Philosophy" initiated by H.M. King Bhumibol and UNESCO's sustainable development dimensions.

The aim of this article was to discuss community participations in Amphawa comprehensive planning, Thailand, which targeted for the year 2030. There were two objectives of the study-to discuss the effectiveness of community participations and to discuss the future land use plan.

\subsection{Limitation of the Study}

The major limitations of Amphawa comprehensive planning were budget and time constraint. Amphawa comprehensive planning was a planning project which received very limited budgets to study while community participation activities were restricted by a

\footnotetext{
* Wannasilpa Peerapun: Tel.: 066-02-2184440

E-mail address: wannasilpa.p@chula.ac.th
}

ISSN: 2398-4287@ 2017. The Author. Published for AMER ABRA by e-International Publishing House, Ltd., UK. This is an open access article under the CC BYNC-ND license (http://creativecommons.org/licenses/by-nc-nd/4.0/). Peer-review under responsibility of AMER (Association of Malaysian Environment-Behaviour Researchers), ABRA (Association of Behavioural Researchers on Asians) and cE-Bs (Centre for Environment-Behaviour Studies), Faculty of Architecture, Planning \& Surveying, Universiti Teknologi MARA, Malaysia.

DOI: http://dx.doi.org/10.21834/e-bpj.v2i5.678 
tight schedule. Other limitation was Thailand's comprehensive planning process mandated by law which strictly outlined steps for plan-making and approvals. As a result, community participation activities and the numbers of participants were limited and the effectiveness of community participation could not be fully addressed.

\subsection{Literature Review}

Comprehensive plans have become common for urban and rural areas because the development is complex, development decisions are interrelated, and the development process could be improved through careful analysis, foresight, and planning (Knaap \& Chakraborty, 2007, p. 19). Successful comprehensive community planning processes are those that are community-driven and all sectors of the community should have an opportunity to participate (Minister of Indian Affairs and Northern Development, 2006, p. 9). Community participations can be classified into several levels. Grabow \& Hilliker $(2006, p$. 27) proposed five different levels of involving citizens in the comprehensive planning process- public awareness (lowest level), public education, public input, public interaction and public partnership (highest level). Several participation techniques were proposed in "CCP HANDBOOK Comprehensive Community Planning for First Nations in British Columbia. Some interesting ones included public hearings, visual preference survey, focus groups, citizen advisory committee, visioning, and citizen planning committees. (Minister of Indian Affairs and Northern Development Ottawa, 2006, pp. 35-48). In Amphawa urban conservation and regeneration projects, it was found that publications and community workshops were very effective multipurpose tools in several planning stages (Peerapun, 2012, p.40).

Sustainable development is the ultimate goal of comprehensive planning. In Thailand, "Sufficiency Economy Philosophy" initiated by H.M. King Bhumibol has been officially adopted and applied to various types of planning. It is the philosophy which stresses three principles in all mode of conduct-moderation, reasonableness and self-immunity (Miller \& Tinio-Le Douarin, 2013, p. 14). Moderation is the idea of people living their lives on the middle path, not to the extreme. Reasonableness refers to people's accumulation of knowledge and experience while self-immunity refers to the ability of people to protect themselves against external turbulence. Two conditions are needed to make these principles work: knowledge and morality. Knowledge encompasses accumulating information with insight to understand its meaning and the prudence needed to put it to use while morality refers to integrity, trustworthiness, ethical behaviour, honesty, perseverance, and a readiness to work hard (Mongsawad, 2010, p. 128).

Another interesting sustainable development model is the one developed by UNESCO (n.d.). It comprises three stacked circles. The middle circle indicates the four dimensions of development-natural, economic, social, and political aspects. The inner circle indicates four major issues associated with the four aspects. The outer layer indicates four means of development-conservation, appropriate development, peace in combination with equity and human rights, and democracy (Peerapun, 2012, p. 38). In "Amphawa urban conservation and regeneration model," the "Sufficiency Economy Philosophy" was put at the heart of the model surrounding by four dimensions adapted from UNESCO's sustainable development model-natural and built environment, economic, social and culture, and politic (Peerapun, 2012, p. 40).

\subsection{Methodology}

The methodology of Amphawa comprehensive planning incorporated significant community participation activities and sustainable development concepts into Thai traditional comprehensive planning process outlined by the Department of Public Construction and Town and Country Planning, Ministry of Interiors (fig. 1).

Mandating by law, a small advisory board was established by Samut Songkhram governor to act as a planning consultant and help monitor the progress of Amphawa comprehensive planning. In terms of community participations, only public hearings at the beginning and the end of the planning process were required. To increase the level of community participations, intensive participation activities were added to the regular planning processes. Community workshops and related activities such as visioning and mapping were adopted as general community participation techniques. They were added into the stages of SWOT analysis, visioning, and planmaking. Due to budget constraint, the number of participants was limited. A working group, comprising 40 local administrators and delegates from all communities in the planning area, was created to participate in planning workshops. In addition, several informal meetings with local administrators and chiefs of sub-district and villages were held to enhance common understandings and community collaborations. In terms of data requirements, data on the natural and built environment dimension were collected mostly from field surveys and feedbacks from local administrators and delegates through the workshops. Data on other dimensions were collected mostly from secondary data collected by related agencies and also from community feedbacks.

In terms of sustainable development, four dimensions adapted from UNESCO's sustainable development model-natural and built environment, economic, social and culture, and politic-were placed at the early stage of data collections and analysis. Sufficiency Economy Philosophy was placed at the heart of the planning process-the stage of visioning where vision and objectives were developed. These concepts helped to shape the scope and directions for Amphawa's future development. 


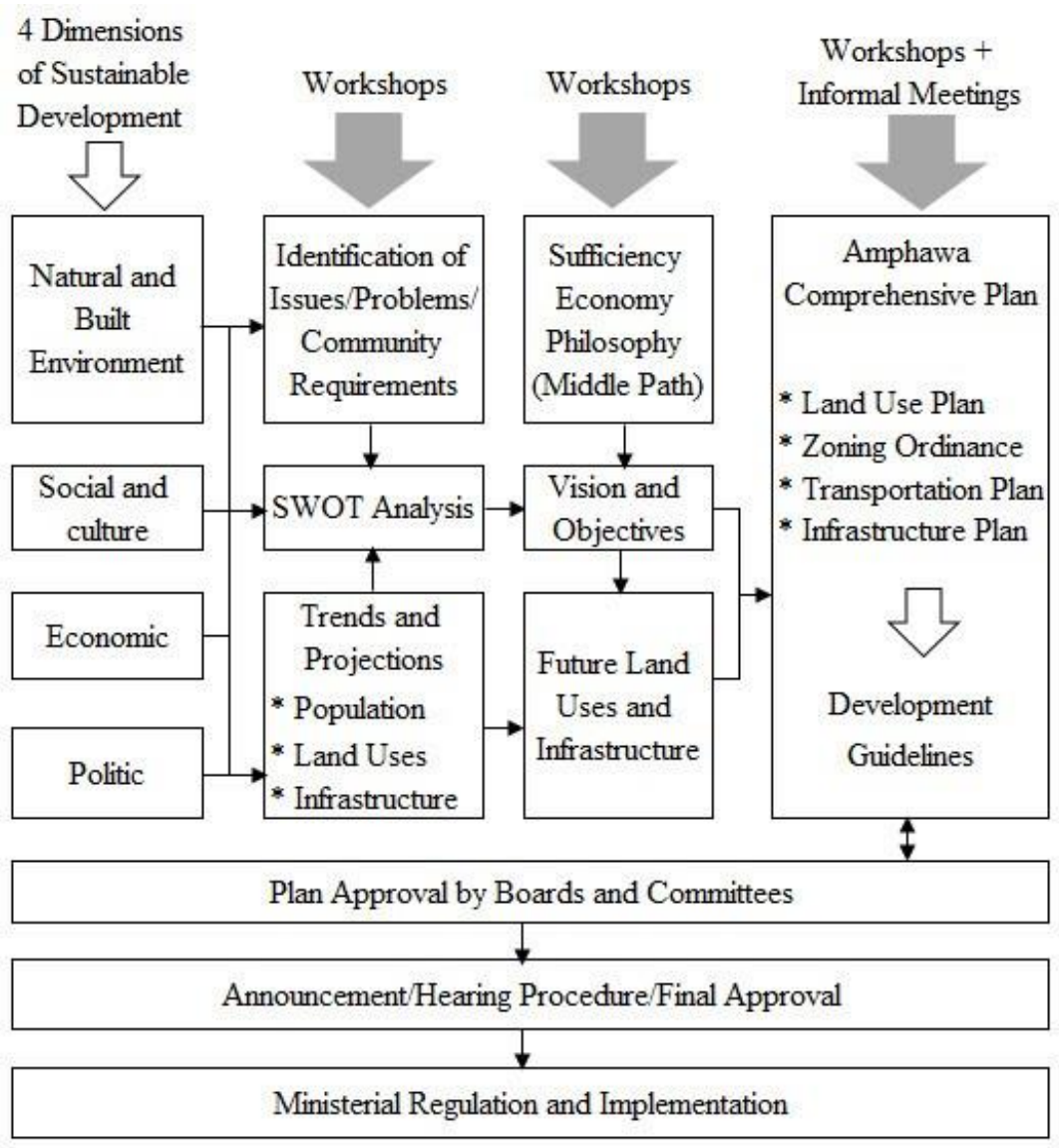

Fig. 1: Amphawa Comprehensive Planning Methodology

\subsection{Results}

Amphawa District covers an area of approximately 170 square kilometers or 41 percent of Samut Songkhram Province. It is located in the western part of Thailand, about 72 kilometers from Bangkok. In 2010, orchards and other agricultural areas accounted for 69 percent of land uses in Amphawa District, following by fish and shrimp ponds (14 percent), mangroves (8 percent) and waterways (4 percent). Residential areas shared only 3 percent while infrastructure and others shared the rest of land uses in Amphawa District (Faculty of Architecture, C.U., 2013, p. 4/27). Land transportation via small road networks along orchard boundaries was the major transportation mode of the area while water transportation was used mostly for tourism purposes. There were 56,755 registered inhabitants in Amphawa District in 2010 (Faculty of Architecture, C.U., 2013, p. 4/27). Major occupations of the people were fruit gardeners, public servants and tradesmen. In terms of tourism development, there were 558,326 visitors coming to Amphawa District, generating 402.17 million Bath of income in 2007 (Peerapun \& Silapacharanan, 2011, p. 174).

\subsection{The effectiveness of community participations in Amphawa comprehensive planning}

Stakeholders engaging in Amphawa comprehensive Planning could be classified into two groups:

1) Appointed committees who were appointed by law and ministerial orders from local, provincial, sub-national and national levels. A small local advisory board was appointed to follow up every plan-making stage. After a draft comprehensive plan had been completed, it had to get approval from Provincial Town and Country Planning Subcommittee, (National) Town and Country Planning Subcommittee and (National) Town and Country Planning Committee respectively.

2) Community participants who participated in various plan-making stages. The law only required a public hearing from local residents after the draft comprehensive plan was completed, not during plan-making stages. Since no real community participations were in action, serious conflicts between appointed committees and community citizens might arise as in the case of Muang Samut Songkhram comprehensive planning which was undertaken earlier. Thus, the missing real "community participants" were added to Amphawa comprehensive planning. A working group comprising 40 members of all mayors, all chief-executives of sub-districts, and delegates from all communities in Amphawa District was formed to participate in planning development activities.

Several planning workshops were arranged utilizing some successive planning tools learned from Amphawa conservation and regeneration projects. Some of them included visioning, community mapping, and small group discussions. In addition, several informal meetings were arranged with all local administrators, sub-district chiefs and village chiefs to promote common understandings, discuss, and follow up the comprehensive plan. Since this group of administrators and chiefs already had monthly 
informal meetings to discuss economic and development issues, it was easy to ask them to comment the comprehensive plan and give recommendations for plan correction during the plan-making stage.

Working group participations were very effective in the stage of plan-making. By dividing participations into small groups and using community mapping technique, alternative future land use maps were quickly developed. They were assembled, discussed and revised several rounds by the whole working group until the final version got approved. Informal meetings with local administrators, sub-district chiefs, and village chiefs were also very effective. Since all the mayors and sub-district administrators were parts of the working group, they understood the situation and the details of the comprehensive plan. With their helps, it was easy to explain the plan to the rest and to ask for recommendations. The feedback from the informal meetings was very good. The sub-district chiefs and village chiefs felt positive to be part of community participants in Amphawa comprehensive planning because the opinions and recommendations were taken into account during plan-making stage. Instead of seeing the plan when it was completed, their roles had changed to ones of community participants. They felt that they know what was going on during the planning process and could explain the situation to local residents under their responsibilities.

After the draft Amphawa comprehensive plan had been completed, it was presented to the Provincial Town and Country Planning Subcommittee for approval. This subcommittee, headed by Samut Songkhram governor, consisted of lieutenant governors, all sheriffs, all provincial chief executives, chief executive of Samut Songkhram Town and Country Planning Office, all chief executives of public agencies in the province, the president of agricultural occupational class, the president of Samut Songkhram Commercial Chamber, the president of Samut Songkhram Industrial Chamber and all local administrators in Samut Songkhram Province. The effectiveness of having local administrators in the working group was obvious at this stage. Since they had participated in several planning stages, including plan-making, they strongly supported the plan. Not only having no comments but also helped to defend the plan. As a result, Amphawa comprehensive plan was quickly approved by the Provincial Subcommittee.

There were some difficulties for Amphawa comprehensive plan to get approval from the National Town and Country Planning Subcommittee. Many changes were made to land use plan and road network specified in the expired Amphawa comprehensive plan. Commercial and high residential areas were reduced and replaced by conservation areas. Some roads which had not been constructed were canceled while the sizes of some roads were reduced. With the supports from local administrators, however, the problem of land use changes was resolved after the subcommittee made a trip to Amphawa and saw the situation there. The subcommittee finally approved Amphawa land use plan without alterations. There were no problems with road cancellation, but some with road size reductions. The new roads proposed in the draft plan were small to conserve the ditch patterns of the orchards while the transportation expert of the subcommittee suggested that the roads should be wider to cope with future demands. The problems was solved via an informal consultation with the expert and applying the concept of the middle path of Sufficiency Economy Philosophy to get the solution. The new road sizes were altered to be wider than the original draft plan but narrower than the expert's original suggestion. Traffic management was proposed to help reduce future transportation problems.

A Public hearing opening for all stakeholders was conducted after the draft comprehensive plan was approval by the Town and Country Planning Subcommittee. There were no problems with future land use plan but some with future road network. Although several roads proposed in the expired comprehensive plan were canceled, some of them had to remain to support future land development and increasing cars. Some local residents did not want any roads to pass their lands for fear that their lands might be unappropriated and for the reason that some lots had been developed during the time lacks between the expired and the new comprehensive plans. The subcommittee did not agree with these local residents and insisted the road network should not be changed from the ones proposed in the draft comprehensive plan. Although there were some problems with future transportation plan, Amphawa comprehensive planning took a shorter time and had fewer problems than other comprehensive planning, especially when compared with Muang Samut Songkhram comprehensive planning. These were due largely to community participation activities incorporated into the planning process.

\subsection{Amphawa future land use plan}

The Amphawa comprehensive plan was a blueprint for physical development framework for Amphawa District until the year 2030. The planning area was expanded from Amphawa Municipality and surrounding areas to the whole Amphawa District. The target population was projected to be 85,152 inhabitants- 60,823 registered inhabitants and 24,329 non-registered inhabitants. The target tourists coming to the area was projected to be $884,787-265,436$ overnight visitors and 619,351 daytime visitors (Faculty of Architecture, C.U., 2013, p. 4/24).

The main idea of Amphawa future land use plan was based upon the vision centered by Sufficiency Economy Philosophy. Moderate development was identified as balancing new development with traditional land use and transportation patterns. Sustainable development was identified as conserving traditional waterfront settlements, orchard, ditch networks, and natural and cultural heritages while recognizing new development as part of Amphawa future. Conservation related areas and new development areas for future needs were designated to co-exist with each other. Only new land uses which meet vision requirements and were compatible with existing land uses were allowed. Land uses for annoying activities and polluting industries were strictly prohibited.

In contrast with the expired comprehensive plan, which favored new development and ignored local identities and heritages, the new Amphawa comprehensive plan addressed the significance local identities and the needs for conservation of heritage places and cultural tourist attractions. Land use zoning was rearranged to reduce population density and development density. Several conservation related areas were designated to keep existing land use patterns. In the new Amphawa future land use plan, land uses were classified into two groups. The first group focused on conservation of existing settlement patterns, cultural heritages, cultural tourism, and agricultural areas. It comprised four types of land uses-residential conservation areas, heritage conservation areas, 
cultural tourism conservation areas, and rural and agricultural conservation areas. The second group focused on corresponding development for future needs. It comprised eight types of land uses-low density residential areas, medium density residential areas, commercial and high density residential areas, rural and agricultural areas, schools and educational institutes, temples and religious areas, public institutes and infrastructure areas, and recreational and open space areas. To keep existing land use pattern, building heights were limited to 7.5 meters for the first group and 10 meters for the second group. Building sizes were limited to 2,000 square meters for both groups.

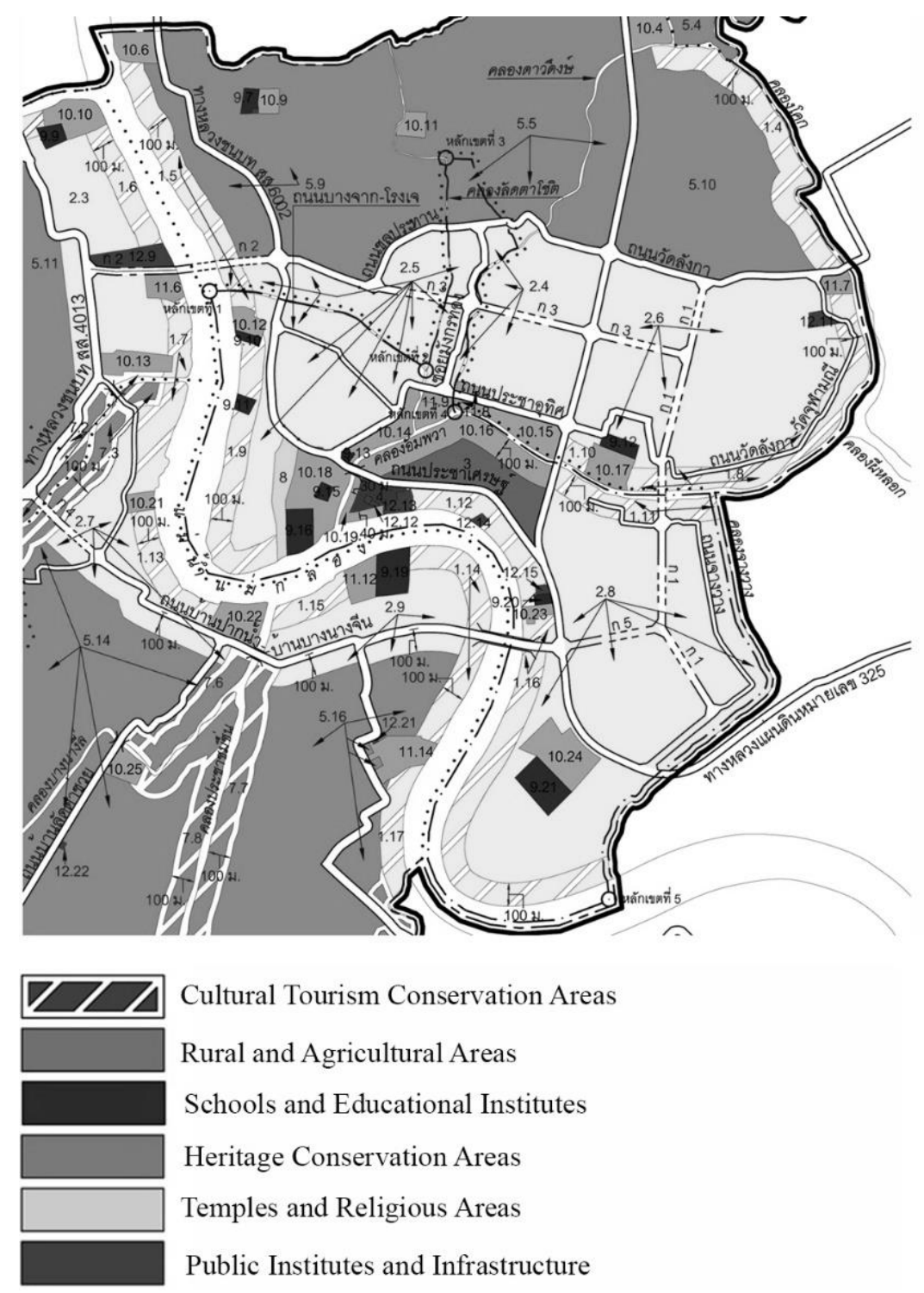

Fig. 2: Future land uses of Amphawa Municipality and surrounding areas in Amphawa comprehensive plan 2030 Source: Faculty of Architecture, C.U. (2013) p. 7/2). 


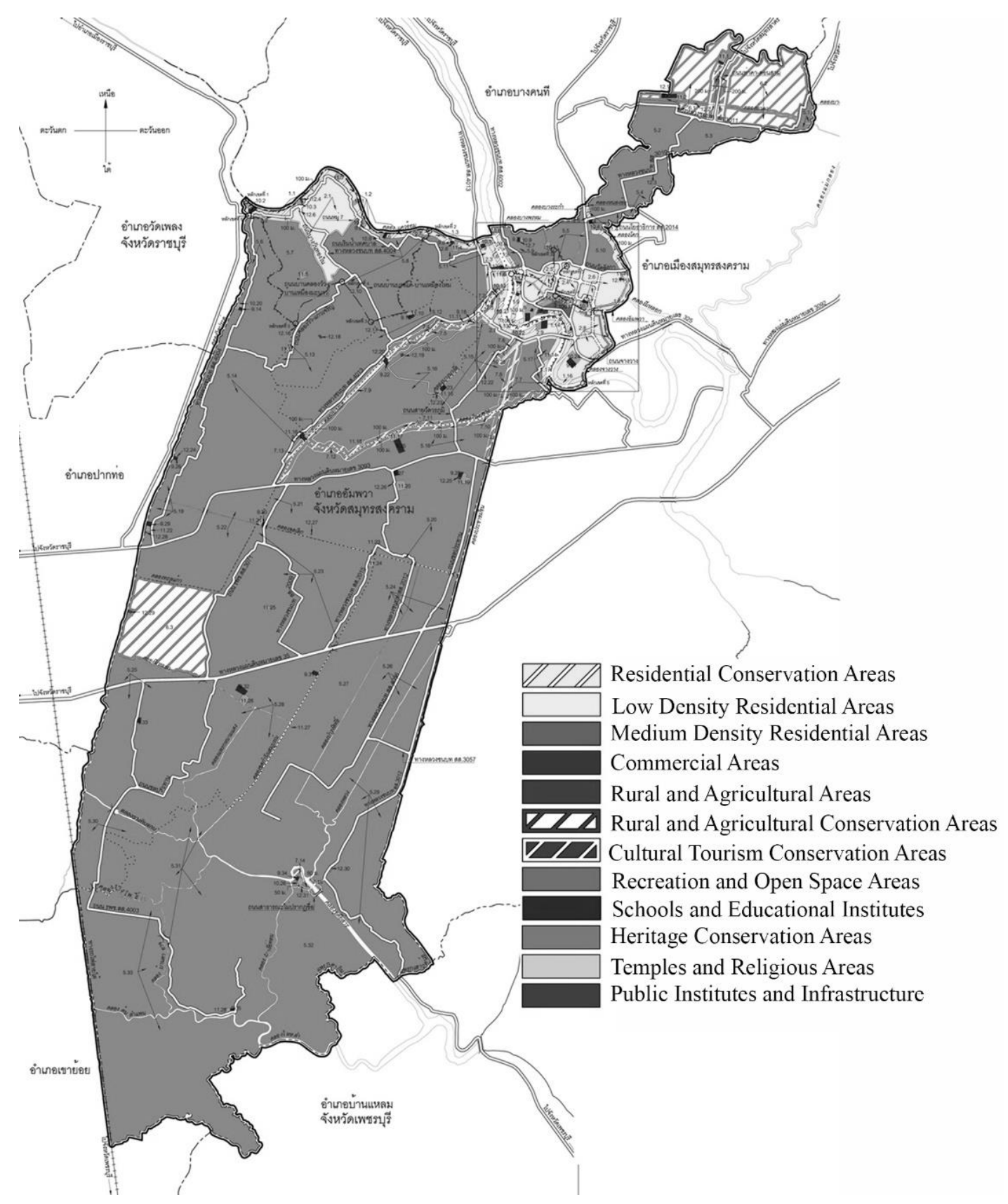

Fig. 3: Future land use plan of Amphawa District in Amphawa comprehensive plan 2030 Source: Faculty of Architecture, C.U. (2013) p. 7/2).

Transforming land use zoning from the old comprehensive plan to the new one was a difficult task. In normal norm, one would expect to see more intensive development as time passed by. In the case of Amphawa comprehensive planning, the situation reversed-the intensity of future land uses was reduced. As mentioned earlier, there was some difficulties to get approval from Town and country Planning Subcommittee. With efficient community participations, the problems were quickly resolved.

Other major changes were made to road network and road sizes. The expired comprehensive plan proposed several roads and bridges cutting through waterfront communities and Amphawa Canal. Fortunately, they had not been constructed due to budget constraint and slow development. These roads and bridges were taken out from the new comprehensive plan. The old plan also proposed several roads surrounding Amphawa Municipality. The road widths, which varied from 14 to 20 meters, were incompatible with existing orchards and ditch systems which were plentiful in the Amphawa District. In order to reduce the needs for land appropriations and the destruction of ditch systems, the new Amphawa comprehensive plan replaced these roads with smaller 6 to 9meter widths. As mentioned earlier, there were some difficulties in doing so and the problems were solved via informal consultation with the expert and applying the concept of the middle path of Sufficiency Economy Philosophy to get the solution. The new road sizes were altered to be 2 meters wider to incorporate footpaths at both sides and traffic management plan was add to cope with traffic congestions which might arise in the future. 
Although land use control of Amphawa comprehensive plan was more intensive than others, it did not cover architectural design which was important when local identities and cultural heritages were considered. To cope with the problem, architectural development guidelines were developed to help guide local administrators and residents for building design. To make the guidelines easy to understand, comparative sketches of desirable and undesirable development and designs were presented in the plan.

\subsection{Discussions}

Although there were budget, time and procedural limitations, community participants in Amphawa comprehensive planning were intensive. The number of participants may seem small at the beginning of the process but it proved to be a manageable size. Every participant had enough opportunity and time to express his concerns and to participate in visioning and plan-making stages. Planning workshops, which were effective techniques for community participations in Amphawa conservation and regeneration projects, proved to be very effective in Amphawa comprehensive planning too. In combination with successive tools such as SWOT analysis, visioning and community mapping, the workshops always ended up with useful and reliable outcomes. The roles of the planner were significant to the success of planning development, however. At the beginning of the planning process, the planner played the role of mentor and coordinator. At visioning stage, the planners became inquirers and summarizers. At the plan-making stages, the planner became the leader of the planning team which consisted of all participants participating in the workshops. Areal based small working group was more effective than large working group when dealing with areal based issues and plans. Large working group was more effective when data assembly and plan assembly were required.

It was found that the combination of local administrators and community delegates came out right. The appearance of local administrators - mayors and chief executives of sub-districts - both in the working group and in Provincial Town and Country Planning Subcommittee proved to be very beneficial because they always supported the plan. Conflicts with local administrators, which usually happened in general comprehensive planning, were totally prevented. Informal meetings with local administrators, chiefs of sub-districts and village chiefs was very useful in terms of promoting common understandings, seeking for local supports and reducing conflicts.

Community participations were very effective for Amphawa comprehensive planning because they helped reduce conflicts and save time. Amphawa future land use plan was unique in terms of designating several conservation related zones and proposing small road network which were unusual for Thai comprehensive plan. The plan was made possible with the support of the communities which was the result of community participations in various stages. It demonstrated the effectiveness of community participations in comprehensive planning. Applying community participations in Thai comprehensive planning had a limitation, however. Due to the nature of Thai comprehensive planning practices, plan approval was undertaken by committees appointed by central government. Since community participations could not have happened at this stage, the highest level of citizen involvements in comprehensive planning — public partnership — proposed by Grabow \& Hilliker (2006, p. 27) could not be reached. In the case of Amphawa comprehensive planning, it was found that the level of citizen involvement could be elevated from public awareness founded in traditional comprehensive planning to public input and public interaction.

\subsection{Conclusion and Recommendations}

Amphawa comprehensive planning for the year 2030 was a big step of community participations in Thai comprehensive planning. Community participations were raised from only from the lowest level of citizen participations to nearly highest level. The effectiveness of community participations in Amphawa comprehensive planning was praised by Town and Country Planning Committee during a committee meeting to approve Amphawa comprehensive plan. In addition to approving the plan, the committee also made the following comments:

The current Amphawa comprehensive planning was undertaken in accordance with local citizen participations. With the supports from local administrators and citizens, the plan was obviously developed to reduce population density. This reflected citizens' awareness of traditional community conservation. The plan also proposed guidelines for planning implementation which should be developed into action area plans. These good things should be a model for other comprehensive planning in the future. (Town and Country Planning Committee, 2013, p. 11)

Generally speaking, the value of community participations in Amphawa comprehensive planning not only came from the effectiveness in terms of time saving and consensus buildings but also came from the ability to draw people to come together to envision the future of their communities. The comprehensive plan which was once perceived by local communities as "their plan" finally became "our plan." Amphawa comprehensive planning offered useful lessons on comprehensive planning in Thailand. The lessons were not fully completed and required further study. More participation techniques and tools should be tested in future comprehensive planning. The analysis should be made, and best combinations of techniques and tools for community participation in comprehensive planning should be addressed.

\section{Acknowledgements}

The author gratefully acknowledge Samut Songkhram Province and Samut Songkhram Town and Country Planning Office for their helps and financial supports and all participants for their cooperation and contributions in Amphawa comprehensive planning. 


\section{References}

City of Greensburg. (2008). Greensburg Sustainable Comprehensive Plan. City of Greensburg: Kansus+BNIM.

Faculty of Architecture, C.U. (2013). Amphawa Comprehensive Plan (2nd revision), Amphawa District, Samut Songkhram Province. Bangkok: Author.

Grabow, S.H. \& Hilliker, M. (2006). Comprehensive Planning and Citizen Participation. UW Extension: Board of Regents of the University of Wisconsin System.

Knaap, G. \& Chakraborty, A. (2007). Comprehensive Planning for Sustainable Rural Development. JRAP. 37(1), 18-20.

Miller, M. \& Tinio-Le Douarin, M.L. (Eds.). (2013). Towards a Sufficiency Economy: A New Ethical Paradigm for Sustainability. Paris: the United Nations Educational, Scientific and Cultural Organization.

Minister of Indian Affairs and Northern Development Ottawa. (2006). Comprehensive Community Planning Handbook. Minister of Public Works and Government Services Canada.

Mongsawad, P. (2010). The Philosophy of the Sufficiency Economy: A Contribution to the Theory of Development. Asia-Pacific Development Journal. 17(1), 123-143.

Peerapun, W. (2009). Changes in the Use of Canalside Buildings on Amphawa Canal, Samut Songkhram Province: The Consequences of Conservation and Development Project from 2001-2009. NAKHARA. 5, 23-38

Peerapun, W. (2012). Participatory Planning Approach to Urban Conservation and Regeneration in Amphawa Community, Thailand. Asian Journal of EnvironmentBehaviour Studies. 3 (7). 35-44.

Peerapun, W. \& Silapacharanan, S. (2011). Conservation and Regeneration of Amphawa Community. In Chulalongkorn University, Sufficiency Economy Vol. 2, pp. 153-184. Bangkok: Chulalongkorn University Press.

Town and Country Planning Committee. (2013). Minute No. 2/2013. Friday 25thJanuary 2013, Rancho Room, Chanwee resort and Country Club, Nakhon Ratchasima Province.

UNESCO. (N.D.). Four Dimensions of Sustainable Development. Retrieved November 20, 2016 from http://www.unesco.org/education/tlsf/TLSF/theme_a/mod04/ uncom04t01s03.htm 